\title{
XXIX. Notices of the results of the labours of continental chemists
}

\author{
Messr. W. Francis \& Messr. H. Croft
}

To cite this article: Messr. W. Francis \& Messr. H. Croft (1841) XXIX. Notices of the results of the labours of continental chemists, Philosophical Magazine Series 3, 19:123, 184-195, DOI: 10.1080/14786444108650397

To link to this article: http://dx.doi.org/10.1080/14786444108650397

册 Published online: 01 Jun 2009.

Submit your article to this journal

Џ Article views: 2

Q View related articles $₫$ 
been obtained with other bases, such as soda, barytes, magnesia, lime, and the oxides of zinc and lead. On the contrary, the heat developed by each base is peculiar to itself; and, consequently, the same acid gives different elevations of temperature, with equivalents of different bases. To take, as an example, the nitric acid, which also produces very nearly the mean quantity of heat given by all the acids, the following numbers express the increments of temperature obtained on combining the same quantity of it with each base:-magnesia, $8 . \mathrm{J}^{\circ}$; lime, $7.2^{\circ}$; barytes, $6.9^{\circ}$; potash, $6.8^{\circ}$; soda, $6.5^{\circ}$; ammonia, $5.6^{\circ}$; oxide of zinc, $4 \cdot 8^{\circ}$; oxide of lead, $4 \cdot 2^{\circ}$; oxide of silver, $3 \cdot 2^{\circ}$. The numbers for barytes, potash, soda and ammonia, are strictly comparable with one another (except a slight correction for differences in the specific heats of the solutions); but in the case of the other bases, an absorption of heat, unknown in amount, takes place in consequence of their conversion from the solid to the fluid state. Hence the numbers for these bases are all below the truth.

Two singular anomalies are described as occurring in the combinations of the peroxide of mercury with the hydracids, and in those of the hydrocyanic acid with the bases.

In confirmation of the second law, the author adduces a series of experiments, which prove, that during the conversion of a neutral into a supersalt no heat is produced. Thus while the normal development of heat occurs when a solution of caustic potash is neutralized by oxalic acid, the subsequent additions, first of one, and afterwards of two more atoms of the same acid, so as to convert the neutral oxalate into the binoxalate, and the latter again into the quadroxalate of potash, are not accompanied by any change of temperature in the solutions. In testing the accuracy of this law, it is necessary to select examples where all the compounds are soluble in water, otherwise the heat arising from the formation of precipitates would interfere with and complicate the result.

The second law does not extend to the case of the conversion of neutral into basic compounds,-a part of the subject which the author has carefully investigated.

XXIX. Notices of the Results of the Labours of Continental Chemists. By Messrs. W. Francis and H. Croft.

[Continued from p. 49.]

Preparation of Urea.

THE usual method of preparing urea by precipitating it from urine by means of nitric acid, is attended with great expense of time and material. Prof. Liebig has recently published the 
following new and easy method :-Twenty-eight parts of perfectly dried ferrocyanate of potash are mixed with fourteen parts of the black oxide of nuanganese, both finely powdered, the mixture heated on a smooth iron plate, (not in a crucible) over a coal fire, to incipient redness, stirring frequently. The mass on cooling is washed out with cold water, and the liquid mixed with twenty and a half parts of dry sulphate of anmonia. It is advantageous to place aside the first strong ley obtained, and to dissolve the sulphate of arnmonia at the common temperature in the last water, and to add this to the first concentrated solution. Usually a strong precipitate of sulphate of potash is immediately formed, from which the liquid is separated by decantation; it is then evaporated in the water bath or on some warm place, boiling being avoided, and the liquid poured off, as long as it is possible, from the deposit of sulphate of potash. It is then evaporated to dryness and treated with boiling alcohol of 80-90 per cent., which dissolves the urea, while the sulphate salts remain undissolved. In this manner nearly four ounces of perfectly colourless and beautifully crystallized urea may be obtained from a pound of the ferrocyanate of potash. It frequently happens that the solution containing the sulphate of potash and urea is coloured yellow by ferrocyanide of ammonium, or of potassium, which dissolves in the alcohol, and gives to the crystals of urea a yellowish colour; it may easily be separated by the addition of a solution of copperas, after separation of the Prussian blue carbonate of ammonia is added to the liquid, which deconposes the excess of iron salt, and the liquid becomes clear and colourless, and may then be evaporated and treated as above. (Ann. de Chem. und Pharm. vol. xxxviii. part 1.)

\section{Arseniuretted Hydrogen.}

It is well known that a solution of the perchloride of mercury most easily decomposes arseniuretted hydrogen, on which account it is employed not only to destroy every trace of this gas, but likewise to indicate its presence. The composition of this precipitate, which is yellow with a slight brownish tinge, and is thus distinguished from the precipitate produced by the action of perchloride of mercury on phosphuretted hydrogen, is quite unknown; Stromeyer seems to be the only person who has examined it. According to him, arseniuretted hydrogen forms, with a solution of perchloride of mercury, arsenious acid and protochloride of mercury, and, finally, an amalgam of mercury and arseric. The precipitate decomposes by preservation in much water; it becomes black, and consists at last only of globules of mercury; the liquid above it contains hydro- 
chloric and arsenious acids. This decomposition is perfectly similar to that which is caused by water in the precipitate produced in solutions of the perchloride of mercury by phosphuretted hydrogen, only that it is effected more rapidly. The similar decomposition of both precipitates by water, and also by dilute nitric acid, supposes a similarity in their constitution, which was confirmed by a quantitative analysis, according to which the precipitate proved to be composed according to the formula $\mathrm{As}^{2} \mathrm{Hg}^{3}+3 \mathrm{Hg}$ Cl. This precipitate differs from that produced by phosphuretted hydrogen, by its being anhydrous, while the latter contains three atoms of water. This is the reason of their different action at a high temperature. The precipitate produced by antimoniuretted hydrogen in solutions of the perchloride of mercury, has quite a different composition to that produced by phosphuretted or arseniuretted hydrogen in such solutions. Whence we may conclude that the composition of antimoniuretted hydrogen differs from those of phosphuretted and arseniuretted hydrogen. ( $\mathbf{H}$. Rose in Pogg. Ann. li. p. 423.)

\section{On the Salts of Lead formed by Nitrous Acid and Hyponitrous Acid.}

Proust was the first to observe that lead dissolves in considerable quantity when brought into a hot solution of the nitrate of lead; the salt thus produced is deposited in the form of yellow lustrous scales. Proust concluded from this experiment that the oxide of lead was reduced to a lower degree of oxidation; however, Berzelius subsequently showed that the solution of the lead was effected at the expense of the nitric acid in the salt employed. About the same time Chevreul described two different salts produced by the action of different quantities of lead on the nitrate of lead, and arrived at nearly the same conclusions as Berzelius. Péligot has recently shown that three very distinct salts are formed by the action of lead on the nitrate of lead, two of which contain not nitrous acid*, as supposed by Berzelius and Chevreul, but hyponitric acid t; accordingly the latter acid, which, according to Dulong's analyses, consists of two volumes of nitrogen and four of oxygen, would, contrary to the general opinion, be able, if not to combine directly with bases, yet at least to exist in combination with them. Proust's salt is best prepared by bringing together one equivalent of lead and one equivalent of the nitrate; the reaction proceeds to the last at a temperature below $60^{\circ}$ or $70^{\circ}$, without any evolution of ni-

- Hyponitrous acid of the English chemists.

$\uparrow$ Nitrous acid of the English chemists. 
tric oxide; this gas escapes only when the yellow salt is decomposed at a higher temperature. Should this salt be mixed with any of the orange-coloured salt which will presently be noticed, it may, from its far greater solubility, be separated from it by treating the mixture with a quantity of warm water, not sufficient to dissolve the whole. The analysis consisted in the direct determination of the oxide of lead, nitrogen and water; the results agree with the formula $\mathrm{N} \mathrm{O}^{4}, 2 \mathrm{~Pb} \mathrm{O}, \mathrm{HO}$. Berzelius adopts hypothetically that it contains 6.4 per cent. water; experiment affords but $3 \cdot 2$. The following simple equation, $\mathrm{NO}^{5}, \mathrm{PbO}+\mathrm{Pb}+\mathrm{HO}=\mathrm{NO}^{4}, 2 \mathrm{PbO}, \mathrm{HO}$, gives good account of the origin of the salt. The second salt is of an orange colour, and is obtained by dissolving two and a half equivalents of lead in the boiling solution of one equivalent of the nitrate of lead; on cooling, a mixture of the yellow and orange salts is obtained; the former is removed with boiling water: All the analyses of this salt give the formula $\mathrm{N} 2 \mathrm{O} 8,7 \mathrm{PbO}, 3 \mathrm{HO}$. The constitution of this salt is confirmed by synthesis, for when the bibasic hyponitrate is boiled with oxide of lead, the orange-coloured salt is obtained. Continued boiling of nitrate of lead with more than two or three equivalents of lead gives Chevreul's rose-red salt, which is represented by the formula $\mathrm{NO}_{3}, 4 \mathrm{~Pb} \mathrm{O}, \mathrm{HO}$. (Compt. Rend. t. xi. p. 860.)

\section{Deville on Oil of Turpentine.}

M. Deville calls the oil which is contained in the artificial camphor Camphen, that in the fluid product Tereben. Tereben may be obtained by distilling oil of turpentine with sulphuric acid. The temperature must not exceed $200^{\circ}$, for then colophen passes over. By repeated distillation with sulphutic acid, the tereben may be obtained pure; the only proof of its purity is its having lost all power of rotation. By distilling the liquid camphor with lime it cannot be obtained pure. It has the same boiling point and specific gravity as oil of turpentine. Formula $\mathrm{C}^{20} \mathrm{H}^{32}$. Tereben combines with the hydrochloric, hydriodic and hydrobromic acids in two proportions. The monohydrochlorate of tereben is $\mathrm{C}^{20} \mathrm{H}^{32}+\mathrm{H} \mathrm{Cl}$; the bihydrochlorate is $\mathrm{C}^{20} \mathrm{H}^{32}+\mathrm{H}^{2} \mathrm{Cl}^{2}$. This latter was examined by Soubeiran and Capitaine; it is the liquid product obtained in preparing artificial camphor; it has probably no power of rotation. The monohydrochlorate is obtained by passing hydrochloric acid into tereben; it is liquid; specific gravity at $20^{\circ}=0.902$; smells like camphor ; contains four volumes of vapour of tereben, and two of hydrochloric acid. 


\section{Notices of the Labours of Continental Chemists.}

Power of rotation $=0$, which is the case with all the other compounds of this class. The monohydrobromate is a colourless fluid; specific gravity $=1.021$ at $24^{\circ}$; obtained by acting on tereben with hydrobromic acid, and purifying by means of chalk, animal charcoal and chloride of calcium.

The bihydrobromate is obtained with the camphen compound by acting on oil of turpentine with hydrobromic acid; it is difficult to procure in a pure state; its power of rotation could not, therefore, be accurately determined. The monohydriodate is obtained in the same manner. Sp. gr. $=1.084$ at $21^{\circ}$; decomposes by exposure to the air. The bihydriodate can only be obtained mixed with the camphen compound.

By the action of chlorine and bromine on tereben, chlorides and bromides are produced. The specific gravities are respectively, 1.360 and 1.978 at $20^{\circ}$. Formulæ $\mathrm{C}^{20} \mathrm{H}^{24} \mathrm{Ci}^{8}$, $\mathrm{C}^{20} \mathrm{H}^{24} \mathrm{Br}^{8}$; eight atoms of hydrogen have been replaced by eight atoms of chlorine or bromine. By distilling these conpounds two others may be obtained, $\mathrm{C}^{20} \mathrm{H}^{28} \mathrm{Cl}^{4}$, or $\mathrm{C}^{20} \mathrm{H}^{28} \mathrm{Br}^{4}$. The monochloride of tereben, $\mathrm{C}^{20} \mathrm{H}^{28} \mathrm{Cl}^{4}$, has a specific gravity $=1 \cdot 1.37$ at $20^{\circ}$.

The action of iodine appears to be more complicated.

Hydrobromate and hydriodate of camphen may be obtained in the same manner as the hydrochlorate; the former is solid; power of rotation $=-0.4264$. The hydriodate is a fluid. Sp.gr. at $15^{\circ}=1.0597$; power of rotation $=-0.1597$. They both decompose by exposure to the air. Formulæ $\mathrm{C}^{20} \mathrm{H}^{32}+$ $\mathrm{H}^{2} \mathrm{Br}^{2}$, and $\mathrm{C}^{20} \mathrm{H}^{32}+\mathrm{H}^{2} \mathrm{I}^{2}$.

By the action of chlorine on hydrochlorate of camphen, a fluid body is first produced, the formula of which is $\mathrm{C}^{20} \mathrm{H}^{24} \mathrm{Cl}^{8}$, $\mathrm{Cl}^{2} \mathrm{H}^{2}$; this body then loses hydrochloric acid and forms a solid crystallized substance, chloride of camphen, $\mathrm{C}^{20} \mathrm{H}^{24} \mathrm{Cl}^{8}$. Chloride of camphen has no power of rotation; sp. gr. at $8^{\circ}=$ 1.50 ; melts at $110-115^{\circ}$. By its distillation another chloride is formed, the formula of which is probably $\mathrm{C}^{20} \mathrm{H}^{28} \mathrm{Cl}^{4}$.

Oil of turpentine is decomposed by chlorine and bromine, and forms two bodies, whose formulæ are $\mathrm{C}^{20} \mathrm{H}^{24} \mathrm{Cl}^{8}$, and $\mathrm{C}^{20} \mathrm{H}^{24} \mathrm{Br}^{8}$. The power of rotation of the chlorine compound is (for the yellow ray) $+0 \cdot 2854$.

Colophen is formed, as above stated, by the action of sulphuric acid on oil of turpentine; it passes over at a temperature above $200^{\circ}$. Formula $\mathrm{C}^{20} \mathrm{H}^{32}$; specific gravity at $9^{\circ}=$ 0.940 ; boils at $310-315^{\circ}$; sp. gr. of its vapour is $11 \cdot 13$.

Colophen is also formed by the rapid distillation of colophonium, but is always impure. Deville supposes that Unverdorben's pinic and sylvic acids are respectively oxides of colophen and tereben ; for, by the distillation of colophonium, 
a product is also obtained which is probably tereben, but mixed with a large quantity of colophen. Chloride of colophen is crystallizable. Formula is probably $\mathrm{C}^{40} \mathrm{H}^{64} \mathrm{Cl}^{8}$. Colophen also combines with hydrochloric acid, but the compound is decomposed by treatment with carbonate of lime, \&c. \&c.(Annales de Chimie et de Phys., t. lxxv. p. 37.)

On the AEthereal Oils. By Gerhardt and Cahours.

Ethereal oils are mixtures of two substances, a hydrocarbon and a peculiar oil containing oxygen. The hydrocarbon may be driven off by distillation, but cannot thus be obtained pure; this is only effected by means of fused potassa. By the action of this substance on the oil, the hydrocarbon is separated, and the peculiar oil, which was combined with the hydrocarbon, is converted into an acid. By thus treating Roman caraway oil (Cuminum Cyminum), cuminic acid is obtained; from oil of valerian (Valeriana officinalis) and Roman oil of camomile (Anthemis nobilis), valerianic acid is obtained. The hydrocarbons contained in these two last-mentioned oils are different; that from oil of valerian is true camphogen, and oxidizes in the air with great rapidity, forming camphor. The hydrocarbon from caraway oil is called cymen; the body, which is changed into an acid by means of potassa, is cuminol.

Cuminol may be obtained by distilling oil of caraway at a temperature of $200^{\circ}$; cymen mixed with cuminol passes over, and cuminol remains behind, which may then be distilled in an atmosphere of carbonic acid. Its formula is $\mathrm{C}^{20} \mathrm{H}^{24} \mathrm{O}^{2}$; sp. gr. of the vapour $5 \cdot 24$, according to calculation $5 \cdot 094$. It is colourless, boils at $220^{\circ}$, absorbs oxygen and becomes acid; this change takes place more rapidly when a base is present to saturate the so-formed acid. By means of bichromate of potassa and sulphuric acid, it is also converted into cuminic acid. Aqueous chlorine acts in the same manner, also strong nitric acid. Cuminic acid is best obtained by dropping the oil into fused potassa, the mass is then dissolved in water and precipitated by nitric acid. Cuminic acid is white, crystallizable, sublimes in beautiful needles, melts at $92^{\circ}$, boils at $250^{\circ}$; formula $\mathrm{C}^{20} \mathrm{H}^{24} \mathrm{O}^{4}$. By the action of potassa on cuminol, two atoms of water are decomposed, hydrogen is set free, and two atoms of oxygen taken up for the formation of cuminic acid; almost insoluble in cold water; somewhat soluble in dilute acids; easily soluble in alcohol and æether. The silver salt has the formula $\mathrm{C}^{20} \mathrm{H}^{22} \mathrm{O}^{3}, \mathrm{Ag} \mathrm{O}$. By heating this salt a carburet of silver, $\mathrm{Ag} \mathrm{C}$, is obtained. Cuminic æther is obtained by saturating an alcoholic solution of cuminic acid with hydrochloric acid, heating and distilling over oxide of lead. 
It is a colourless liquid, lighter than water, boils at $240^{\circ}$; insoluble in water, soluble in alcohol and æther. Formula $\mathrm{C}^{20} \mathrm{H}^{22} \mathrm{O}^{3}, \mathrm{C}^{4} \mathrm{H}^{10} \mathrm{O}$. Specific gravity of vapour $=6.65$, calculated 6.583.

By the action of potassa on cuminol, without the aid of heat, a peculiar gelatinous substance is formed-cuminol-potassium (potassio-cuminol), $\mathrm{C}^{20} \mathrm{H}^{22} \mathrm{~K} \mathrm{O}^{2}$. This is decomposed by water into cuminol and potassa; it absorbs oxygen and forms cuminate of potassa. Chloride of cuminol is obtained by acting with chlorine or cuminol in the sunlight. The chloride is a colourless fluid, but decomposes with great rapidity. Formula $\mathrm{C}^{20} \mathrm{H}^{22} \mathrm{Cl}^{2} \mathrm{O}^{2}$. Forms, by boiling with potassa, cuminate of potassa and chloride of potassium ; by exposure to a moist atmosphere it also forms cuminic acid. An amide compound does not appear to exist. The action of bromine is exactly the same as that of chlorine. By distilling one part of cuminic acid with four parts of caustic baryta, a colourless oil is obtained, and carbonate of baryta remains in the retort. This oil is cumen; it is colourless; smells like benzin; boils at $144^{\circ}$; formula, $\mathrm{C}^{18} \mathrm{H}^{24}$; sp. gr. of the vapour $=3.96$, calculated $4 \cdot 12$. Cumen, $\mathbf{C}^{18} \mathbf{H}^{24}$, is cuminic acid, minus carbonic acid, $\mathrm{C}^{20} \mathrm{H}^{24} \mathrm{O}^{4}-\mathrm{C}^{2} \mathrm{O}^{4}$. Cumen is insoluble in water; soluble in alcohol and ether; forms, with anhydrous sulphuric acid, a peculiar compound-cumensulphuric acid. The baryta salt crystallizes in beautiful lamellæ. Formula $\mathrm{C}^{18} \mathrm{H}^{22}, \mathrm{~S}^{2} \mathrm{O}^{5}+\mathrm{BaO}$. Retinyl (Retinylène) has the same formula as cumen; it boils, however, at $150^{\circ}$; it combines in the same manner with sulphuric acid. The baryta salt, however, forms only crystalline crusts. Formula is the same, viz. $\mathrm{C}^{18} \mathrm{H}^{22}, \mathrm{~S}^{2} \mathrm{O}^{5}+\mathrm{BaO}$. It also differs from the cumensulphate in being insoluble in absolute alcohol.

By the distillation of one part of cinnamic acid with four parts of caustic baryta, a similar fluid, cinnamen, may be obtained. Formula, $\mathrm{C}^{16} \mathrm{H}^{16} ; \mathrm{sp} . \mathrm{gr}$. of the vapour $=3.55$, calculated $=3.57$; boils at $140^{\circ}$. Bromine forms with it a crystalline compound, $\mathrm{C}^{16} \mathrm{H}^{18} \mathrm{Br}^{4}$.

Cymen is obtained pure by treating the oil of caraway with fused potassa, by which means all cuminol is separated. $\mathrm{Cy}-$ men is colourless; boils at $165^{\circ}$; soluble in alcohol and æther; forms, with fuming sulphuric acid, the cymensulphuric acid: forms, with nitric acid, a new acid, which is difficultly crystallizable. Formula of cymen is $\mathrm{C}^{20} \mathrm{H}^{28}$; sp. gr. of vapour $=$ $4 \cdot 59,4 \cdot 70$, calculated 4.69 .

Cymensulphate of baryta has the formula $\mathrm{C}^{20} \mathrm{H}^{26}, \mathrm{~S}^{2} \mathrm{O}^{5}+$ 
$\mathrm{BaO}+2 \mathrm{aq}$. It is isomeric with Delalande's camphensulphate, \&c.-(Annales de Chim. et de Phys. III. t. i. p. 60.)

On account of the great length of this memoir, many imperfectly examined, and not as yet analysed substances, have been passed over in this abstract without notice. Liebig's remarks, moreover, showing that the French type is nothing more than radicai, could not be extracted without encroaching too much on other important papers.

\section{On the Action of Potassa on Indigo-blue.}

Fritzsché has continued his researches on Anilin, a substance which had been previously described by Unverdorben under the name of Crystallin, as has been already mentioned. (Notices, Phil. Mag., s.3, vol. xviii.p.280.) The action does not commence until the potassa solution is very concentrated and has been boiled some time; the boiling point must be as high as $150^{\circ}$. If the solution be kept at this temperature, and pure indigo-blue added from time to time, the whole is dissolved, forming a yellowish red liquid, in which, after a time, crystals are formed; it is then better to stop the operation and allow the whole to crystallize. By this operation hardly a trace of any volatile substance is formed, and no gas evolved. A small quantity of a dark-coloured substance is formed with the yellow potash salt, from which it cannot be separated; it appears to be an accidental product. If the whole crystallized mass be treated with water, this dark coloured substance causes a formation of indigo-blue, but the excess of potassa also acts on the yellow salt, and indigo-blue is precipitated. It is better therefore to saturate the greater part of the potassa in the solution with an acid. A bluish green precipitate is formed, and by filtering a golden-yellow fluid is obtained, out of which acids precipitate a voluminous flocky reddish-brown body-chrysanilic acid. The colour of this new acid is similar to that of kermes mineral. It is not at all crystalline, assumes a darker colour by drying. It is very little soluble in water, easier soluble in alcohol; from a concentrated solution in a mixture of water and alcohol it may be obtained in a crystalline state. It dissolves in alkalies with a golden-yellow colour, but care must be taken not to use an excess of alkali, for then the fluid becomes green. The metallic salts are insoluble, lead and zinc salts are of a beautiful red colour. The formula is not as yet determined; the results obtained do not agree well with one another. By dissolving chrysanilic acid in dilute sulphuric acid two new bodies are formed, one of which crystallizes out on cooling, the other remains dissolved. The soluble one has received the name of Anthranilic acid, 


\section{Notices of the Labours of Continental Chemists.}

It may be prepared in another way. The crystalline mass obtained by acting on indigo-blue with potassa is dissolved in alcohol, and allowed to stand exposed to the air until its greenish colour has passed into brown. A stream of carbonic acid is then passed through the solution in order to saturate the free alkali, and the alcohol is distilled off after the carbonate of potassa has been separated. On concentration, anthranilate of potassa crystallizes out in thin lamellæ, the mother liquor is separated by bibulous paper, the salt dissolved in as small a quantity of water as possible, and acetic acid added, which produces a crystalline precipitate of hydrated anthranilic acid. Anthranilic acid is, when pure, perfectly colourless, has a sweet taste even when in combination with alkali. If the decomposition of the potassa salt be conducted very slowly it may be obtained in scaly crystals, like benzoic acid. It is difficultly soluble in cold water, easier in boiling water. In alcohol and æther it is easily soluble. It melts at $135^{\circ}$, and sublimes; at a higher temperature it is decomposed. The alkaline salts are soluble, the copper, zinc and lead salts are crystalline powders. The formula of the hydrated acid is $\mathrm{C}^{14} \mathrm{H}^{12} \mathrm{~N}^{2} \mathrm{O}^{3}+\mathrm{H}^{2} \mathrm{O}$, that of the silver salt $\mathrm{C}^{14} \mathrm{H}^{12} \mathrm{~N}^{2} \mathrm{O}^{3}$ + Ag O. Hydrated anthranilic acid heated above its point of fusion is decomposed into carbonic acid and anilin, $\mathrm{C}^{14} \mathrm{H}^{12}$ $\mathrm{N}^{2} \mathrm{O}^{3}+\mathrm{H}^{2} \mathrm{O}=\mathrm{C}^{12} \mathrm{H}^{14} \mathrm{~N}^{2}+2 \mathrm{CO}^{2}$. In an experiment it was found that the carbonic acid was $31 \cdot 49$ per cent. of the employed acid; according to calculation it should be 31.93 . By distilling an anthranilate anilin is also obtained, but the decomposition is much more complicated ; carbon is separated. It has been already stated that by the action of dilute sulphuric acid on chrysanilic acid a substance is obtained which crystallizes as the fluid cools; it is bluish black, soluble in alcohol, with a purple-red colour. After drying it loses this solubility; it is easily decomposed by alkalies; indigo-blue is formed, \&c. (Journal fïr Praktische Chemie, B. 23, p. 67.)

\section{On the Products of the Decomposition of Chloride and Bichloride of Isatin.}

Erdmann has continued his experiments on these highly interesting bodies, and in the following memoir the products of decomposition are examined. When a stream of sulphuretted hydrogen is passed through a solution of chloride or bichloride of isatin, or the analogous bromides, the solution becomes colourless, and a white sediment is formed, consisting of sulphur and a new body, which may be freed from the sulphur by digestion with bisulphuret of carbon. A better method is to dissolve the chlorides in hydrosulphuret of am- 
monium. By standing, or more rapidly by the application of heat, the solution deposits a white substance, which, if quickly washed with water, freed from air, may be obtained pure.

Chlorisatyd (chloride of isatyd?) is a white pulverulent substance. When dried at $120^{\circ}$ assumes a reddish colour. Insoluble in cold water, but little in boiling water; soluble in boiling alcohol. Formula, $\mathrm{C}^{16} \mathrm{H}^{10} \mathrm{~N}^{2} \mathrm{Cl}^{2} \mathrm{O}^{3}$, i. e. chloride of isatin plus 2 atoms of hydrogen. It is not changed by the action of chlorine.

Bichlorisatyd (bichloride of isatyd) is perfectly similar to the protochloride. Formula $\mathrm{C}^{16} \mathrm{H}^{10} \mathrm{~N}^{2} \mathrm{Cl}^{4} \mathrm{O}^{3}$, i. e. bichloride of isatin plus 2 atoms of hydrogen.

Bibromisatyd is very similar, $\mathrm{C}^{16} \mathrm{H}^{10} \mathrm{~N}^{2} \mathrm{Br}^{4} \mathrm{O}^{3}$.

Chlorisatyd heated to $180^{\circ}$ gives off water, in greater quantity at $200^{\circ}$; the remainder in the retort is of a brownish-violet colour. Chloride of isatin sublimes in crystals, and the remaining mass evidently contains more of the same, which, as well as the undecomposed chlorisatyd, may be extracted by boiling alcohol. The insoluble part is pulverulent, dirty violet-coloured, insoluble in water, alcohol and hydrochloric acid; soluble in caustic potash solution with yellow colour. The alkaline solution gives with hydrochloric acid a yellow precipitate, soluble in boiling water. The violet body is chloride of indin. The composition does not appear to be yet accurately determined. Bichloride of indin is obtained in the same manner, and is quite similar; bichlorisatyd, as well as bibromisatyd, are decomposed, however, at a lower temperature than the protochloride (chlorisatyd). Bibromide of indin is of a deep blackish red colour, somewhat soluble in alcohol. Chlorisatyd is easily soluble in a solution of caustic potash; ont of the solution a salt crystallizes, which is chlorisatinate of potassa; out of the mother liquor acetic acid precipitates a yellow body, soluble in boiling water; by boiling the solution (which has been filtered from the yellow matter so obtained) with hydrochloric acid, flocks of a brownish violet substance are precipitated, precisely similar to the above-mentioned chloride of indin. In the fluid is chloride of isatin. Bichlorisatyd behaves exactly similar, only that the salt which first crystallizes out is not bichlorisatinate of potassa. Its solution gives with hydrochloric acid a yellowish white precipitate, soluble in hot water, from which it is deposited by cooling. Formula, $\mathrm{C}^{16} \mathrm{H}^{10} \mathrm{~N}^{2} \mathrm{Cl}^{4} \mathrm{O}^{4}, i$. e. isomeric with the bichlorisatinic acid. The potash salts of these acids are precisely similar; they differ in their decomposition by hydrochloric acid. The actions of nitric acid and ammonia on chloride and bichloride Phil. Mag. S. 3. Vol. 19. No. 123. Sept. 1841. 
of isatin are too little examined to enable us to make any abstract. Chlorine does not appear to exert any action on chloride and bichloride of isatin, when they are suspended in water, or even under the influence of sunlight. If, however, they are dissolved in alcohol, and chlorine is passed through the solution, they are soon decomposed. A thick fluid is formed. When no more of this is produced, the operation is finished. Sal-ammoniac is also formed in large quantity. In the thick oily fluid is suspended a small quantity of shining lamellæ, which may be separated by dissolving the oily fluid in alcohol, after the whole has been freed from sal-ammoniac by means of water. This crystalline substance has received the name of chloride of anil. The alcoholic solution contains hydrochJoric ather; by distillation a resinous mass remains in the retort; it still contains chloride of anil, from which it may be separated by solution in alcohol; if its solution be then distilled, and heated still further, a volatile product is formed, which sublimes in needles. This is called chloruretted chloride of indopten (gechlortes chlorindopten). This substance, when treated with potassa, forms a new acid, chloruretted chlorindoptenic acid (hyperchlorindoptenic acid?). It has great similarity to the chlorindoptenic acid, but its formula is $\mathrm{C}^{12} \mathrm{Cl}^{10}$.

Chloride of anil may be sublimed if carefully heated; insoluble in water, almost so in cold alcohol; soluble in hot alcohol. It is not changed by nitric, sulphuric and hydrochloric acids. Formula $\mathrm{C}^{6} \mathrm{Cl}^{4} \mathrm{O}^{2}$. It dissolves in solution of potassa with a purple-red colour; on cooling brownish purple-red crystals are formed, which contain chloranilic acid. 'The insoluble red silver salt is $\mathrm{C}^{6} \mathrm{Cl}^{2} \mathrm{O}^{3}+\mathrm{Ag} \mathrm{O}$. The potassa salt is $\mathrm{C}^{6} \mathrm{Cl}^{2} \mathrm{O}^{3}, \mathrm{~K} \mathrm{O}+\mathrm{H}^{2} \mathrm{O}$. It explodes on heating. The metallic salts are insoluble. On adding hydrochloric or sulphuric acid in excess to the warm solution of chloranilate of potassa, reddish grains, or sometimes yellowish-red lamellæ of chloranilic acid are precipitated. Dried at $125^{\circ}$ it contains one atom of water, the crystals contain two atoms.(Conclusion in our next.) - (Journal für Praltische Chemie, xxii, p. 257-299.)

\section{OnCatechin (Catechinic Acid) and Pyrocatechin (Pyrocatechinic Acid).}

Wackenroder has examined the properties of catechin, Zwenger the properties and the chemical composition, and Hagen the constitution alone. The formulæ obtained agree neither with one another, nor with those formerly obtained by Svanberg, we need only therefore give those proposed. 
Analogies between the Chemical Rays and Radiant Heat. 195

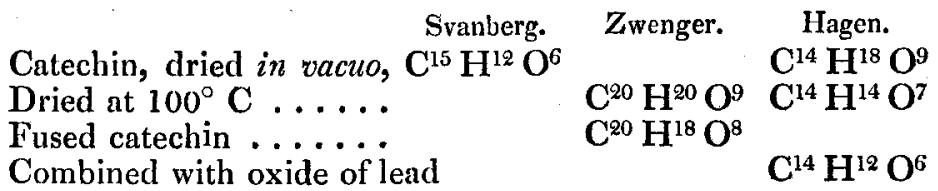

The pyrocatechin has been discovered and examined both by Wackenroder and $Z$ wenger. It is obtained by heating catechin above its point of fusion; white acid vapours are evolved, and a more or less brown coloured acid fluid distils over; by evaporation the pyrocatechin may be obtained crystallized, and may then be purified by sublimation. Melts at $20^{\circ} \mathrm{C}$; ; easily soluble in water, alcohol and zther. The aqueous solution is easily decomposed by exposure to the air. Decomposed by alkalies and their carbonates. Formula $\mathrm{C}^{6} \mathrm{H}^{6} \mathrm{O}^{2}$. In combination with oxide of lead, $\mathrm{C}^{6} \mathrm{H}^{4} \mathrm{O} .-$ (Annalen der Chemie und Pharmacie, xxxvii. pp. 306, 320, 336.)

XXX. On some Analogies betroeen the Phcnomena of the Chemical Rays, and those of Radiant Heat. By JoHN William Drapen, M.D., Professor of Chemistry in the University of New York*. [Illustrated by Plate 1.]

(1.) T T is the object of this memoir, to establish some stri$1 \mathrm{king}$ analogies which exist between the phænomena of the chemical rays and those of radiant heat.

(2.) As most of the experimental illustrations which I shall here give depend upon the use of M. Daguerre's preparation, (though I have numerous others which serve to extend these truths to other combinations, and which will be published in due time,) I shall also incidentally give what appears to be the proper theory of the Daguerreotype.

(3.) Without saying anything of the laws of reflexion, refraction, polarization, and interference, to which these rays are subject, the study of which I commenced more than five years ago on paper rendered sensitive by the bromide of silver, further than that a general similitude holds in all these cases between the rays of heat and the chemical rays, I shall at present confine my observations to establishing the following propositions.

(4.) ist. 'That the chemical action produced by the rays of light, depends upon the ABSORPTION of those rays by sensitive bodies; just as an increase of temperature is produced by the absorption of those of heat.

* Communicated by the Author;

$\mathrm{O} 2$ 